\title{
LOS RELICARIOS DE LOS SANTOS EUSEBIO, COLUMBINO, BONIFACIA Y LUCENCIA DE LA CASA DE MEDINA SIDONIA
}

\section{THE RELIQUARIES OF SAINTS EUSEBIO, COLUMBINO, BONIFACIA AND LUCENCIA OF THE HOUSE OF MEDINA SIDONIA}

\author{
Emilio Ruiz de Arcaute Martínez \\ Servicio de Restauración, Diputación Foral de Álava. España \\ eruizdearcaute@gmail.com
}

\begin{abstract}
A principios del siglo XVI el culto a Santa Úrsula y la posesión de reliquias de las once mil vírgenes tiene un importante florecimiento entre los miembros del círculo cortesano del joven emperador Carlos V. Partiendo de la combinación de estudios técnicos y constructivos, documentación histórica y análisis estilístico e iconográfico se ha podido establecer la conexión entre cuatro bustos relicario, hoy desvinculados y separados por miles de kilómetros, que pertenecieron originalmente a don Juan Alonso Pérez de Guzmán y Zúñiga, VI duque de Medina Sidonia. Este enfoque pluridisciplinar ha permitido relacionar estas obras con un reducido grupo de relicarios, de excelente calidad, producidos en el taller de los Borman en Bruselas.

Palabras clave: busto relicario; Santa Úrsula; duque de Medina Sidonia; Bruselas; Borman.
\end{abstract}

At the beginning of the $16^{\text {th }}$ century the cult of Saint Ursula and the possession of relics of the eleven thousand virgins has an important flourishing between members of the courtier circle of the young emperor Charles V. On the basis of the combination of constructive and technical studies, historical documentation and stylistic and iconographical analysis, it has been established the connection between four reliquary busts, today unlinked and separated by thousands of kilometers, which originally belonged to don Juan Alonso Pérez de Guzmán y Zúñiga, VI Duke of Medina Sidonia. This multidisciplinary approach has made it possible to relate these works with a small group of reliquaries, of excellent quality, produced by the Borman workshop in Brussels.

Keywords: reliquary bust; Saint Ursula; Duke of Medina Sidonia; Brussels; Borman. 


\section{LOS DOS BUSTOS DE LA BASÍLICA DE LA CARIDAD DE SANLÚCAR DE BARRAMEDA}

En el interior del armario relicario situado en una capilla del lado del evangelio de la basílica de Nuestra Señora la Caridad de Sanlúcar de Barrameda, tras la Vanitas pintada al óleo sobre las puertas por el maestro Juan Luis, se encuentran, entre otras piezas, dos bustos relicario de obispos. Como se sabe, esta iglesia es una fundación de la Casa Ducal de Medina Sidonia, erigida por Alonso Pérez de Guzmán el Bueno y Zúñiga, VII duque de Medina Sidonia, y su mujer Ana de Silva y Mendoza. Y seguramente estén allí ubicados desde 1613, como parte de las más de doscientas reliquias que aquel año entregó dicho duque a ese tem$\mathrm{plo}^{1}$. Ambas imágenes representan a miembros masculinos del séquito de Santa Úrsula, entre los que según la leyenda se encontraban también obispos, cardenales y un papa².

El primero de ellos mide $65,5 \times 37$ x $16 \mathrm{~cm}$, sin peana, y está vestido con alba, casulla, rematada al cuello con lista de pedrería, y capa pluvial con capillo, que va decorada con dibujo inciso de rocalla, rematada con orfre dorado de roleos entre líneas de perlas y sujeta por un broche trilobulado que muestra una reliquia cubierta por cristal. Lleva Mitra Pretiosa, adornada con pedrería y dos medallones con rostros de perfil enfrentados en la parte delantera. Las ínfulas tienen decoración de pedrería y bordes de perlas, terminando en una línea de cuatro borlones. Una de ellas reposa sobre el hombro derecho mientras que la otra cae casi verticalmente sobre el capillo (Figura 1).

El segundo, de $64 \times 38,5 \times 16,5 \mathrm{~cm}$, sin peana, igualmente vestido con alba, casulla, rematada con lista de pedrería, y capa pluvial con capillo, decorada con rocalla incisa y con cenefa dorada con borde de perlas y relieve con motivos esquemáticos geométricos y vegetales. La capa está sujeta por un broche tetralobulado

${ }^{1}$ Carta de donación de don Alonso Pérez de Guzmán el Bueno, VII duque de Medina Sidonia, al santuario de Nuestra Señora de la Caridad, de reliquias y relicarios. Traslado notarial del escribano Fernando Parra de 7 de noviembre de 1613. ASHC (Archivo del Santuario y Hermandad de la Caridad), leg. 3, carp. 3, 10 ff. Trascripción de CRUZ ISIDORO, Fernando: El Santuario de Ntra. Sra. de la Caridad, de Sanlúcar de Barrameda. Estudio histórico-artístico. Córdoba, 1997, pp. 345-348. Ver igualmente del mismo autor "La colección pictórica del Palacio sanluqueño de la Casa ducal de Medina Sidonia entre los años de 1588 y 1764", Laboratorio de Arte, 16, 2003, pp. 151-169; "Pintores flamencos e hispanos en la corte del VI duque de Medina Sidonia, de 1540 a 1554", en Archivos de la Iglesia de Sevilla. Homenaje al archivero D. Pedro Rubio Merino. Córdoba, 2006, pp. $143-$ 161; "Arte y Arquitectura en la Sanlúcar del Siglo XVI", en Sanlúcar, la Puerta de América. Estudios Históricos y Artísticos. Sanlúcar de Barrameda, 2012, pp. 227-297; y El Patrimonio restaurado de la Basílica de la Caridad de Sanlúcar de Barrameda. Sanlúcar de Barrameda, 2011.

${ }^{2}$ DE LA VORÁGINE, Santiago: La leyenda dorada. Madrid, 1996, pp. 679-680. 
que también lleva reliquia cubierta por cristal. En la cabeza, la Mitra Pretiosa, adornada con pedrería y dos medallones en la parte delantera, que representan sendos rostros de perfil, femenino y masculino, enfrentados. Las ínfulas, adornadas de pedrería, también terminan en cuatro borlones. Una de ellas reposa sobre el hombro izquierdo mientras que la otra ha perdido los borlones y cae casi verticalmente sobre el capillo (Figura 2). Los dos bustos van colocados sobre una peana de similares características y decoración incisa de rocalla.

Estas piezas han sufrido evidentes transformaciones tanto en soporte y policromía como en las peanas en el siglo XVIII, sin duda debido a su estado de conservación. En ambos casos se ha reconstruido parcialmente la mitra, que ahora se encaja mediante dos gruesas espigas de madera. Originalmente tenían una bisagra y se abrirían haciéndolas girar hacia atrás, por encima del circulus, para mostrar un fragmento de cráneo y su leyenda. El segundo de los bustos conserva en el interior de la mitra la siguiente inscripción: "caput sancti [...] lonbany episcopi de vg natione sancte Orsule" -"cabeza de San [...] lonbany obispo de la nación (de vírgenes) de santa Úrsula- ${ }^{3}$. El extraño remate de los pliegues del lateral derecho de su capa pluvial parece indicar igualmente que la imagen tuvo una mano. Ambos han perdido también elementos decorativos esenciales, como los medallones con representaciones de rostros de perfil que llevarían en la parte trasera de las mitras. Además, los relieves delanteros están tan empastados por la gruesa capa de estuco que dichos personajes son irreconocibles. La repolicromía integral ha terminado de modificar el aspecto de los bustos hasta hacer pensar a Enrique Romero de Torres que se trataba de una talla del siglo $\mathrm{XVII}^{4}$, o que Peter Metz y otros autores afirmen que ambos son copias de otro busto de obispo que se encuentra en el Bode-Museum de Berlín, realizadas en España en torno a $1600^{5}$. A pesar de esos comentarios y de que las citadas transformaciones modifican ostensiblemente su apariencia, desde un primer momento he incluido ambos bustos en el grupo de relicarios del siglo XVI, de origen brabanzón, que es objeto de la investigación de mi proyecto de tesis ${ }^{6}$.

3 Traducción libre del autor.

${ }^{4}$ Describe este y otro busto de santa de Sanlúcar de Barrameda como "talla grabada y policromada del siglo XVII". ROMERO DE TORRES, Enrique: Catálogo Monumental de España. Provincia de Cádiz (1908-1909). Madrid, 1934, p. 516.

5 METZ, Peter: Bildwerke der Christlichen Epochen, von der Spätantike bis zum Klassizismus. München, 1966, pp. 69-70.

${ }_{6}$ Titulado "Estudio de un conjunto de bustos relicarios del siglo XVI, que representan a mártires del séquito de Santa Úrsula, realizados por los Borman, en Bruselas. Puesta a punto de un método de atribución y datación, mediante la combinación de técnicas de estudio histórico-artístico y el análisis constructivo mediante tomografía". Programa de Doctorado Arte y Patrimonio, de la Facultad de Bellas Artes de la Universidad de Sevilla. 
Se trata de un conjunto de veintiséis bustos, que comparten tanto unas características estilísticas que posibilitan situarlos en torno a 1520 como la iconografía, ya que representan a vírgenes y obispos que habrían acompañado a Santa Úrsula en su martirio ${ }^{7}$. Por otro lado, todos parecen estar relacionados con el entorno próximo del emperador Carlos $\mathrm{V}$, compartiendo también unas características técnicas y constructivas que permiten diferenciarlos claramente de otros numerosos relicarios realizados en aquella época ${ }^{8}$. Esto hace pensar en un encargo realizado al taller de los Borman, en torno al mismo tema iconográfico, para destinatarios del entorno cortesano de Carlos $\mathrm{V}$ y en un contexto político e histórico muy concreto. La tradición sostiene que algunos fueron regalos del emperador, pero, aunque es conocida la importancia de este tipo de usos en la corte, hasta la fecha no hay ningún documento que lo pruebe. Por lo que tampoco se puede descartar que se trate de una coincidencia de encargos similares, al mismo taller y en un corto periodo de tiempo, ya fuera por moda o imitación entre distintas familias o por la extendida devoción a Santa Úrsula del momento9.

Hasta ahora hemos podido acreditar que la mayoría de las piezas estudiadas, que no han sido totalmente descontextualizadas, pertenecían a personajes de este círculo próximo al emperador: alta nobleza, Consejos de Estado y de la Inquisición y, con frecuencia, miembros del séquito que le acompañó en el viaje de su coronación por Europa y que estuvieron con él en Colonia. Así, las cuatro imágenes que se encontraban en la Sacra Capilla de Úbeda -tres de ellas desaparecidas durante la guerra civil española- fueron, según la tradición, un regalo de Carlos $\mathrm{V}$ a su secretario don Francisco de los Cobos durante su viaje de coronación a Alemania $^{10}$. Los dos bustos que se encuentran en el Museo de los Caminos de Astorga, procedentes de la capilla de la Trinidad de la colegiata de Villafranca del Bierzo, pertenecieron a don Pedro de Toledo, marqués de Villafranca, que también le acompañó en dicho viaje. Los cinco bustos del Museo Diocesano de Arte Sacro de Vitoria proceden de la antigua capilla de la Cruz o de las Once Mil Vírgenes, fundada en la iglesia de San Vicente por Ortuño Ibáñez de Aguirre, oidor

${ }^{7}$ DE LA VORÁGINE, Santiago: La leyenda..., op. cit.

${ }^{8}$ RUIZ DE ARCAUTE, Emilio: "Busto relicario de Santa Aurelia", en Splendor Europae. Arte Europeo en la Diócesis de Jaén. Jaén, 2012, pp. 94-97; VIDAL, Pilar y RUIZ DE ARCAUTE, Emilio: "Dos bustos relicarios de las once mil vírgenes, de taller alemán del entorno de Colonia, en Joarilla de las Matas (León)", Boletín Real Academia de Bellas Artes de la Purísima Concepción, 47, 2012, pp. 25-34; RUIZ DE ARCAUTE, Emilio: "On the trail of a select group of central European reliquary busts: Using construction typology for authorship attribution”, en SEYMOUR, Kate (ed.): Polychrome Sculpture: Artistic Tradition and Construction Techniques. Glasgow, 2014, pp. 86-93.

${ }^{9}$ FERREIRO, Joaquín: La leyenda de las once mil vírgenes Sus reliquias, culto e iconografía. Murcia, 1991, pp. 114-120.

${ }^{10}$ KENISTON, Hayward: Francisco de los Cobos, Secretary of the Emperor Charles $V$. Pittsburgh, 1958. 
del Consejo Real y de la Inquisición del emperador. Los dos bustos que se encuentran en la iglesia de Santo Tomás de Joarilla de las Matas, en León, pertenecieron seguramente a Juan de Juara, repostero de Isabel la Católica y de su hija, la reina Juana, así como tesorero de las Islas y Tierra Firme del mar Océano.

En el caso de los bustos de Sanlúcar, sabemos que don Juan Alonso Pérez de Guzmán y Zúñiga, VI duque de Medina Sidonia (1518-1558), es nombrado entre los acompañantes del emperador durante su coronación en Aquisgrán. Fue además el peticionario en Portugal de la mano de la futura emperatriz Isabel y ayudó al emperador en la guerra contra el turco. Todo ello demuestra su estrecha relación con Carlos V. Además, en el inventario post mortem del VI duque, realizado en 1558 "1 , aparecen citados: "Dos obispos de bulto, los medios cuerpos con unos escudicos de armas de los Guzmán", refiriéndose sin duda a los relicarios presentes en la iglesia de la Caridad.

\section{ESTUDIO MATERIAL Y TIPOLÓGICO}

Entre las razones para vincularlos con todas estas piezas destacan su semejanza estilística y el parecido de algunos motivos decorativos con los de otros casos, pero sobre todo las coincidencias estructurales con los relicarios del grupo, apreciables ya a partir de la primera documentación fotográfica consultada ${ }^{12}$. Tras un examen directo, además de constatar los abundantes elementos modificados que presentan, se ha podido corroborar su pertenencia al grupo según el estudio material y técnico de las piezas. La leyenda conservada en uno de los bustos, que hace referencia a Santa Úrsula, despeja igualmente cualquier duda sobre su conexión iconográfica. En cualquier caso, el argumento más concluyente para establecer la conexión con este conjunto de bustos es precisamente su coincidencia estructural y constructiva.

El análisis material de los relicarios de Sanlúcar de Barrameda dejó ver que nos encontrábamos ante dos ejemplos que repetían las mismas claves establecidas en la comunicación presentada por Rosaura García y Emilio Ruiz de Arcaute, en la sexta y última reunión del Grupo Latino de Escultura Policromada, celebrada en la Escola Superior de Conservaçâo e Restauro de Lisboa, los días 7 y 8 de mayo de 1999. Dicho estudio, titulado "Aplicación de técnicas de estudio no destructivas en escultura policromada", se basaba en la combinación de

11 ADMS (Archivo Ducal de Medina Sidonia), leg. 942, s. f. Sanlúcar de Barrameda, 26 de noviembre de 1558, Palacio de Sanlúcar. Transcripción de URQUÍZAR, Antonio: Coleccionismo y nobleza. Signos de distinción social en la Andalucía del Renacimiento. Madrid, 2007. pp. 175-207.

12 ROMERO DE TORRES, Enrique: Catálogo Monumental..., op. cit., lámina DXLII; y Fototeca del Laboratorio de Arte, Universidad de Sevilla, imágenes nº 3-2530 y $3-2531$. 
radiografía, endoscopia y tomografía (Figura 3), sobre un grupo de cinco bustos relicarios pertenecientes al Museo Diocesano de Vitoria, completado con analíticas puntuales, y permitió definir una tipología constructiva específica, que facilita la identificación de estas piezas ${ }^{13}$.

Se trata de bustos de bulto redondo muy naturalistas, vestidos a la moda cortesana flamenca y centroeuropea de principios del siglo XVI, de medidas semejantes y perfil estrecho, montados sobre peana. Están tallados en madera de roble albar, traído del Báltico, y compuestos de un gran número de piezas (Figura 4), que depende, por ejemplo, de su complejidad o la presencia o no de manos. La zona central está realizada ensamblando tres bloques trapezoidales, que se corresponden con secciones radiales de aproximadamente 1/16 del tronco, obtenidas por hendimiento - wainscot $-{ }^{14}$, de longitud variable, con una anchura de en torno a $30 \mathrm{~cm}$ y espesor máximo de $7-8 \mathrm{~cm}$, rematados por otro bloque a cada lado. El sistema de ensamblaje es de "uniones vivas" reforzadas con espigas de madera e intercalado puntual de "chuletas" de madera en las juntas. Presentan ahuecado en el interior de cabeza y cuerpo para albergar las reliquias, que se colocan envueltas en ricas telas dentro del relicario. Todos llevan un registro con tapa en la cabeza, a veces también una "teca" en el pecho y en un caso una vitrina en la base, para la contemplación de la reliquia. El único elemento metálico original que llevan es una bisagra, para abrir la tapa, salvo en el de Berlín, cuyo broche es de metal dorado e incrustación de piedras. De talla finísima, tienen elementos decorativos semejantes y sencillo acabado polícromo al óleo, con dorado y plateado realizado "al mordiente" y aplicación puntual de lacas.

Si nos basamos en el estudio estilístico, todo apunta hacia un origen brabanzón y más concretamente de Bruselas. Todas estas obras se caracterizan por su calidad artística. Tanto el naturalismo y el virtuosismo en el tratamiento de los volúmenes, a pesar de que se trata de piezas muy estrechas, como el acabado de

13 Tanto la coherencia del método combinado de estudio como el establecimiento de la tipología constructiva se dieron a conocer en las siguientes publicaciones: GARCÍA, Rosaura y RUIZ DE ARCAUTE, Emilio: "The conservation and restoration of the polycrome scupture in Álava. The main altarpiece of San Vicente de Arana and the bust-reliquaries of the Church of San Miguel de Vitoria", en Polychrome Skulptur in Europa. Technologie, Konservierung, Restaurierung. Dresden, 1999, pp. 84-89; GARCÍA, Rosaura y RUIZ DE ARCAUTE, Emilio: "Técnicas de estudio de la escultura policromada", en Actas del $9^{\circ}$ Congreso Nacional END. Vitoria, 1999, pp. 203-211; GARCÍA, Rosaura y RUIZ DE ARCAUTE, Emilio: "Los Bustos relicarios de las once mil vírgenes. Claves para su estudio", $A K O B E, 1,2000$, pp. 18-21; y GARCÍA, Rosaura y RUIZ DE ARCAUTE, Emilio: "La escultura policromada. Criterios de intervención y técnicas de estudio", Arbor, CLXIX, 2001, pp. 645-676.

${ }^{14}$ GLATIGNY, Jean-Albert: "Medidas, proporciones y huellas de herramientas", en El retablo de la Coronación de la Virgen. Parroquia de la Asunción de Errentería. San Sebastián, 2013, pp. 95-104. 
los detalles o la riqueza del repertorio decorativo, con expresiones plásticas góticas y renacentistas entrelazadas, el tratamiento realista de los diferentes tejidos y paños, la variedad de los tocados y los collares que, a pesar de repetir numerosos elementos, siempre son diferentes, recuerda a otras producciones realizadas por los Borman a finales del siglo XV y principios del XVI.

\section{LA POSIBLE CONEXIÓN CON EL BUSTO DE BERLÍN}

Como ya se ha indicado, por su semejanza se ha querido ver, en mi opinión equivocadamente, en el busto de Berlín el original a partir del cual se habrían realizado posteriormente los dos obispos de Sanlúcar. Primero Metz, después Enciso, Steppe y Levkoff ${ }^{15}$ siguiendo a este sitúan el obispo de Berlín originalmente en España. Hipótesis necesaria para argumentar que los dos bustos de Cádiz son meras copias tardías. Sin embargo, hay que descartar totalmente que los bustos de Sanlúcar sean copias posteriores, como lo demuestran las evidencias materiales. Ya hemos indicado que ambos están realizados con la misma técnica que el resto de piezas del grupo. Los materiales y el modo de ejecución empleados en ellos, que son diferenciadores y específicos, son incompatibles con la fabricación española. Además, hay documentos que los sitúan a mediados del siglo XVI en la colección de Medina Sidonia ${ }^{16}$. Por otro lado, sin descartar que el obispo del Bode-Museum en algún momento hubiese estado en la Península, no se conoce ningún documento que lo acredite.

El busto relicario de Berlín es, en cualquier caso, una pieza clave para la inclusión del conjunto en el contexto de la coronación de Carlos como emperador, ya que presenta varios elementos iconográficos que hacen referencia a dicho evento, dentro de la compleja simbología dinástica de los Habsburgo.

Por un lado, el juego simbólico de los cuatro medallones de su mitra, que relaciona las figuras de Alejandro Magno y Julio César, en la parte frontal, con la de los emperadores Maximiliano I y Carlos V, en la trasera (Figura 5), hace referencia a la legitimidad imperial, basada fundamentalmente en la idea de la traslatio Imperii y con la designación divina o Dei Gratia. Como se sabe, Maximiliano I se esforzó en establecer una relación de continuidad histórica entre el antiguo Imperio Romano y él mismo, que, aunque no estaba basada exactamente en una continuidad genealógica, sí trataba de justificar el derecho natural de los Habsburgo y,

${ }_{15}$ METZ, Peter: Bildwerke..., op. cit., p. 70; ENCISO, Emilio: "Escultura medieval y renaciente", en Catálogo Monumental Diócesis de Vitoria. T. III. Vitoria, 1968, p. 326; STEPPE, Jan Karel: "C36-C39. Atelier Brabançon (?) (vers 1529). C40. Atelier de Cologne (?) (vers 1525-1530)”, en Spledeurs D’Espagne et les villes belges, 1500-1700. Bruselas, 1985, p. 519; y LEVKOFF, Mary L.: "William Randolph Hearst's Gifts of European Sculpture to the Los Angeles County Museum of Art", The Sculpture Journal, IV, 2000, p. 170.

16 ADMS, leg. 942, op. cit. 
por tanto, también de su nieto Carlos como herederos de Carlo Magno a la perpetuación en el trono del Sacro Imperio ${ }^{17}$. Carlos $\mathrm{V}$ es presentado pues en la mitra como el nuevo y legítimo César.

Por otro lado, también es significativa la decoración de su capillo, que representa a la Virgen María Apocalíptica coronada (Figura 5), muy parecida a la Virgen del capillo de la capa pluvial que Carlos V regaló a la iglesia de Santiago de Sevilla -hoy en la catedral- con motivo de su boda con la emperatriz Isabel en 1526, y que, según la tradición, habría utilizado en 1520 durante su coronación en Aquisgrán. Esta iconografía mariana está también íntimamente relacionada con el contexto de su coronación, no solamente porque en ambos casos María aparece coronada, sino porque según la tradición, vinculada a la aparición de la Virgen Apocalíptica al emperador Augusto ${ }^{18}$, se le consideraba como la protectora de los emperadores. Indudablemente con esa intención, desde 1524, cuelga del centro de la bóveda gótica de la catedral de Aquisgrán un "Marianum" realizado por Jan van Stevensweert.

Carlos V, como heredero a la cabeza de los Austrias y a la jefatura del imperio, también utilizó el complejo entramado simbólico de carácter político-religioso, elaborado por su abuelo Maximiliano I, para "sacralizar" la dinastía y justificar su derecho al trono imperial. Ambos utilizaron emblemas con la efigie de la Virgen Apocalíptica para defender la legitimidad moral de la perpetuación de la dinastía Habsburgo al frente del Sacro Imperio Romano ${ }^{19}$. Una iconografía que, con su evolución hacia la de la Inmaculada Concepción, fue uno de los estandartes religiosos de las distintas ramas de la Casa de Austria y de la Pietas Austriaca. El busto de Berlín representa un alegato justificativo de la coronación de Carlos V, utilizando el argumentario elaborado por Maximiliano I. Por un lado, se apoya, con los retratos de los medallones, en la continuidad de la línea

${ }^{17}$ SILVER, Larry: Marketing Maximilian. The Visual Ideology of a Holy Roman Emperor. Princeton, 2008, pp. 79-80; y VILÀ, Lara: "Virgilio y la construcción simbólica del poder en el Renacimiento", en Actas del VIII Congreso "Cultura Europea". Pamplona, 2007 , p. 7.

${ }^{18}$ Según la tradición que se recoge en La leyenda dorada, Albunea, la sibila Tiburtina, hizo que el emperador Octavio Augusto contemplase una maravillosa aparición en la que "surgió alrededor del sol un círculo de oro y dentro de él la imagen de una virgen hermosísima con un niño en su regazo", profetizando el nacimiento de Cristo. DE LA VORÁGINE, Santiago: La leyenda..., op. cit., p. 56. Esta leyenda está estrechamente relacionada con el pasaje descrito en el Libro del Apocalipsis, capítulo 12, versículo 1: "Y una grande señal apareció en el cielo: una mujer vestida del sol, y la luna debajo de sus pies, y sobre su cabeza una corona de doce estrellas".

${ }^{19}$ HACKENBROCH, Yvonne: Enseignes. Renaissance Hat Jewels. Florencia, 1996, p. 193; y GARCÍA, José Julio: "Emblemas portátiles: El empleo de divisas metálicas como adorno de sombreros y vestimentas, y su función en el origen del género emblemático", Imago, 7, 2015, p. 17. 
imperial y, por otro, en su carácter católico, con la inclusión de la Virgen Apocalíptica. Nos encontramos, pues, no solo ante un relicario que representa a un santo mártir de la congregación de Santa Úrsula, sino también ante un instrumento político de la propaganda carolina.

\section{EL ORIGEN DE LOS DOS BUSTOS DE SAN SIMEÓN}

Como hemos visto, el estudio de los aspectos técnicos, estilísticos e iconográficos permite relacionar todos los bustos con un mismo taller y contexto histórico. Sin embargo, no podemos establecer, con un mínimo de fiabilidad, la pertenencia de todos los relicarios del grupo a familias concretas del entorno cortesano del emperador Carlos V. Muchas de estas obras han sido dispersadas como consecuencia de las guerras, las desamortizaciones, el empobrecimiento de sus propietarios ${ }^{20} \mathrm{y}$, especialmente, por el expolio sufrido por el patrimonio artístico español durante el siglo XIX y principios de $\mathrm{XX}^{21}$, perdiéndose la información sobre su procedencia. Obras que, sin duda, se ubicaban originalmente en oratorios privados, capillas familiares o colecciones artísticas nobiliarias españolas, siguiendo el gusto y la moda de la corte de los Austrias ${ }^{22}$. Como ocurre con diez de los bustos del grupo, que después de haber salido de España en su mayoría de forma irregular y tras haber pasado por diversas colecciones privadas, se encuentran en importantes museos de Europa y Estados Unidos.

Hoy sabemos que los dos bustos del Museo Nacional de Cataluña, en Barcelona, pertenecieron a la colección de Luis Paindiura i Pou hasta 1932. El busto del Bode-Museum de Berlín perteneció a la de Ole Olsen hasta 1944. Uno de los cuatro bustos del Metropolitan Museum de Nueva York perteneció a la colección de Henry Hirsch hasta 1931, después a la de Henri Heilbronner hasta 1959. Otro, a la colección Louis Mohl hasta 1912, después a la de Stephen Carlton Clarck hasta 1967. Otro también perteneció a la de Louis Mohl hasta 1912, después a otra colección privada hasta 1976. Mientras que el último perteneció

${ }^{20}$ PÉREZ-FLECHA, Javier: "La Colección de Mobiliario de José Weissberger en el Museo Nacional de Artes Decorativas de Madrid", Res Mobilis, 6-II, 2016, p. 372.

${ }^{21}$ PÉREZ, Fernando y SOCÍAS, Inmaculada: La dispersión de objetos de arte fuera de España en los siglos XIX y XX. Barcelona, 2011; SOCÍAS, Inmaculada y GKOZGKOU, Dimitra: Agentes, marchantes y traficantes de objetos de arte (1850-1950). Gijón, 2012; MERINO DE CÁCERES, José Miguel y MARTÍNEZ, María José: La destrucción del patrimonio artístico español. W. R. Hearst: el gran acaparador. Madrid, 2112; y LEVKOFF, Mary L.: Hearst the Collector. Los Ángeles, 2008.

${ }^{22}$ URQUÍZAR, Antonio: Coleccionismo y nobleza..., op. cit.; CHECA, Fernando y MORÁN, José Miguel: El coleccionismo en España: de la cámara de maravillas a la galería de pinturas. Madrid, 1985; y HELMSTUTLER DI DIO, Kelley y COPPEL, Rosario: Sculpture Collections in Early Modern Spain. Farnham, 2013. 
a la colección Bourgeois Frère, después a la del barón Albert von Oppenheim hasta 1904, luego a la de M. J. Seligmann hasta 1906 y, más tarde, a la de J. Pierport Morgan y sus herederos hasta 1917. El del LACMA de Los Ángeles perteneció a la colección Louis Mohl hasta 1912, después a la de William Randolf Hearst hasta 1948. Los dos del Hearst Castle-California State Parks, de San Simeón, también estuvieron en la de Louis Mohl ${ }^{23}$ hasta 1912, después en la colección de la familia Ruiz -Pedro, Raimundo y Luis Ruiz- hasta 1921, y luego a W. R. Hearst. Por último, hay un busto del que sólo sabemos que, en 1893, pertenecía a Frederic Spitzer ${ }^{24}$.

Interesante información, reflejo de una azarosa vida por distintas colecciones, salas de subastas y ventas. Pero, al fin y al cabo, una información incompleta, ya que carecemos de datos que nos indiquen la colección y el lugar de procedencia de estos bustos. Sigue habiendo amplias zonas grises que hacen dudar de la legitimidad de las primeras transacciones que hicieron salir estas obras de territorio español.

Sin embargo, sí que hemos podido establecer un origen común en el caso de dos de los relicarios que aparecen citados en el catálogo de la colección Mohl ${ }^{25}$. Se trata de dos de los bustos de vírgenes que finalmente terminaron en posesión de Hearst y aún siguen en el castillo de San Simeón.

La primera imagen, con unas dimensiones de 47,6 x 44,5 x 19,5 cm, sin peana, ricamente ataviada con camisa que llega hasta el cuello, vestido liso con amplio escote en pico, rematado con lista de pedrería, que termina en el pecho en una teca redonda cubierta de cristal y pequeño escote triangular trasero. Un galón decorado con roleos recoge las mangas abullonadas y acuchilladas, que dejan salir tela de la camisa. Va además adornada al cuello con cadena de eslabones redondos, de la que cuelga una joya. La cabeza presenta un tocado con crespina, acabada en la nuca con un tranzado que cuelga por la espalda, adornado por una cinta de tela que recorre la cabeza desde la zona central de la frente, cayendo inclinada por la espalda hasta el hombro derecho, donde se pliega para llegar al busto.

${ }^{23}$ Que cinco de los bustos aparezcan citados con los números 78, 79, 81, 82 y 83 en MOHL, Louis: Catalogue des bois sculptés, principalement des XVe et XVIe siècles, statuettes bustes, groupes, bas-reliefs importante série de casse-noisettes; cabots, têtes de mort coupe en buis, meubles et sièges composant la collection de feu M. Louis Mohl. París, 1912, cuya venta tuvo lugar el 14 de mayo de dicho año, pudiera hacernos pensar en un origen común de todos ellos. Pero teniendo en cuenta la variedad de dicha colección y el diverso origen de sus piezas no hay ninguna razón para ello.

${ }^{24}$ CHEVALLIER, Paul y MANNHEIM, Charles: Catalogue des Objets d'Art et de Haute Curiosité. Antiques, du Moyen-Age \& de la Renaissance, Composant l'Importante et Précieuse Collection Spitzer. París, 1893, p. 80 y lám. XXIV.

${ }_{25}$ MOHL, Louis: Catalogue des bois..., op. cit., p. 22. 
A los lados del tocado, el pelo sale recogido en largas trenzas que se entrelazan sobre la frente, para caer sobre el pecho (Figura 6).

La segunda, de 47,6 x 41,2 x 19,05 cm, sin peana, también ricamente engalanada con camisa que llega a la altura del esternón, brial decorado con brocado de motivos vegetales y escote cuadrado que se remata con una lista de pedrería y perlas. Está cubierta con manto liso, cuyo fiador va fijado a ambos lados por broches redondos y anudado en el centro del pecho. Tiene al cuello colgante de cordón dorado de dos vueltas con joyel. La cabeza lleva tocado, con crespina y grandes discos, decorado con perlería, sujeto por una banda frontal, otra superior y otra trasera. El pelo sale del tocado cubriendo casi uniformemente toda la espalda, mientras que por delante unos mechones sueltos reposan a cada lado del manto (Figura 7).

Ambos bustos presentan registro con tapa cuadrada en lo alto de la cabeza para poder ver la reliquia, van montados sobre la peana original, con los escudos de la Casa de Medina Sidonia en el frente y el de los Reyes Católicos a los lados (Figura 8). En ambos casos también la policromía parece haber sufrido modificaciones parciales. Como se ve, ambos comparten una característica que los diferencia del resto de los relicarios del grupo: presentan en sus bases los escudos de armas de Medina Sidonia y los Reyes Católicos. Este es un elemento, en cierto modo distorsionador de la imagen que comparten con las otras veinticuatro piezas del conjunto, que ha hecho dudar a algunas personas de su originalidad, planteando que pudiera tratarse de añadidos relativamente recientes. Pero como sabemos no era extraño en aquella época que muchas obras de carácter religioso y más concretamente relicarios, incorporasen escudos de armas, divisas, leyendas o cualquier otro elemento identificador del patronazgo de la familia.

En mi opinión, en este caso, la presencia de los escudos hace posible identificar al propietario original de los bustos, que no sería otro que don Juan Alonso Pérez de Guzmán y Zúñiga, VI duque de Medina Sidonia, quien probablemente mandara añadirlos, bien durante su realización o bien cuando las obras se encontraban ya en Sanlúcar. En cualquier caso, se trataría de las "Dos vírgenes que también tienen los escudos de las armas de Guzmán en los cuerpos" y que aparecen enumeradas inmediatamente después de los "Dos obispos de bulto, los medios cuerpos con unos escudicos de las armas de Guzmán", en el inventario post mortem de VI duque de Medina Sidonia, ya mencionado ${ }^{26}$. Esto nos permite considerar los dos obispos de Sanlúcar y las dos vírgenes de San Simeón como parte de un mismo grupo de cuatro bustos, que en el siglo XVI incluían en su decoración los mencionados escudos de armas. Igualmente hace posible imaginar el aspecto de las peanas y la decoración originales de los obispos (Figura 8).

${ }^{26}$ ADMS, leg. 942, op. cit. 
Otro documento hace referencia a estas piezas como parte del mismo conjunto. Se trata de una bula del papa Clemente VII, fechada en Roma, el 12 de julio de $1532^{27}$, por la que se conceden indulgencias relacionadas con las "reliquias de las once mil Vírgenes, y cavezas de San Eusebio, Columbino, y las de las Santas Bonifacia y Lucencia". Este texto prueba la presencia de los relicarios en la colección del VI duque en aquella fecha, refutando aún más la hipótesis de su realización posterior, y nos permite conocer los nombres de los personajes representados en los bustos relicario, identificando al obispo que conserva la leyenda incompleta: "sancti [...] lonbany" como el San Columbino de la bula. Crombach menciona un Columban entre los obispos que embarcan con Santa Úrsula ${ }^{28}$. Ambos obispos son igualmente citados en el listado de la carta de donación de reliquias al santuario de la Caridad como "san Eusebio obispo y mártir" y "san Columbario" 29 , refiriéndose seguramente al San Columbano.

Puede que los cuatro bustos se incorporaran, en un primer momento, al oratorio del desaparecido palacio sevillano de los Guzmanes ${ }^{30}$, aunque seguramente se instalasen en la iglesia de Santa María de la O de Sanlúcar, a la que se accedía por un pasadizo desde el palacio ${ }^{31}$, cuando el VI duque traslada su residencia a dicha villa (1523-1524) ${ }^{32}$. Sabemos que, a mediados del siglo XVI, se procesionaban los relicarios en fechas señaladas, como por ejemplo el día del Corpus en $1543^{33}$ y en $1551^{34}$, o que, en el XVII, el día de Todos los Santos también salían en procesión 163 reliquias de la Caridad ${ }^{35}$, donde ya estaban los obispos. Celebraciones de

27 ADMS, leg. 936.

28 'On s'enbarque donc; cinc Evefques fe mettent de la partie: Guillaume (que les autres nomment Michel) Columban, Iuain, Eleuthere, Lothaire, tous coufins, ou alliés de l'efpoux, ou de l'efpoufe". CROMBACH, Hermann et alt.: La gloire de S. Ursule. Valentiennes, 1656, p. 8. p. 345 .

${ }^{29}$ CRUZ ISIDORO, Fernando: El Santuario de Ntra. Sra. de la Caridad..., op. cit,

${ }^{30}$ CRUZ ISIDORO, Fernando: "El Palacio sevillano de los Guzmanes según dos planos de mediados del siglo XVIII", Laboratorio de Arte, 19, 2006, p. 257.

${ }^{31}$ PÉREZ GÓMEZ, M ${ }^{\mathrm{a}}$ de la Paz: "Planimetría del siglo XVIII del palacio de los Medina Sidonia en Sanlúcar de Barrameda", Laboratorio de Arte, 23, 2011, p. 343.

${ }^{32}$ MORENO OLLERO, Antonio: "La capilla musical de Don Juan Alonso de Guzmán”, en Actas del II Congreso Internacional In Medio Orbe. Sanlúcar de Barrameda, 2016, p. 179.

33 Ibidem, p. 183.

${ }^{34}$ Información facilitada por don Antonio Romero Dorado, investigador que está realizando su tesis con el título "La capilla palatina de los duques de Medina Sidonia y la iglesia mayor de Sanlúcar de Barrameda: historia de una dualidad y de una hibridación".

${ }^{35}$ CRUZ ISIDORO, Fernando: El Santuario de Ntra. Sra. de la Caridad..., op. cit, p. 48 
exhibición pública de reliquias -ostensio reliquiae-asociadas tradicionalmente a la concesión de indulgencias.

Quedan de todas formas dudas por resolver. No sabemos cómo y cuándo se separaron dichas piezas. Lo más lógico es pensar que las dos mártires que se encuentran en la colección del Hearst Castle nunca llegaran a formar parte de la donación del VII duque de Medina Sidonia a la iglesia de la Caridad de Sanlúcar de Barrameda, ya que según se estableció en el documento notarial de donación de 7 de noviembre de 1613: "Y es mi determinación de adjudicarle las dichas reliquias y hacerle donasción dellas por contrato entre bibos, para que perpetuamente mientras el mundo durare estén en la dicha iglesia... y para que esto tenga efecto y se perpetué, guarde y cumpla en la más bastante forma que puedo y en derecho lugar aya, otorgo y conozco por esta presente carta que por mi y en nombre de mis herederos y subcesores necesarios y particulares y por quien de mi o dellos título y causa oviere de poseer en cualquier manera, adjudico y hago pura y real cessión, renunciación buena, pura, perfecta, acavada e ynrrebocable de las que el derecho llama entre vivos, dada de mi mano a la dicha casa e iglesia de la Santísima Virgen de la Caridad desta ciudad de todas las reliquias que abaxo yrán declaradas y de los relicarios en questán" ${ }^{36}$. No pudiendo salir de la iglesia de la Caridad ni ser reclamadas por sus herederos al quedar vinculadas a dicha fundación.

Todo parece indicar que la separación se debió producir en el periodo entre el inventario post mortem, de 1558, y la donación de reliquias a la iglesia de la Caridad, en 1613. Desconocemos los motivos exactos de dicha división, pero el VI duque dejó múltiples deudas. Y según consta en su testamento, de agosto de 1556, dejaba como herederos a sus nietos don Alonso y doña María Andrea, nacidos del matrimonio de su difunto hijo Juan con Leonor de Zúñiga y Sotomayor, nombrando como albaceas a esta y a su hermano, el conde de Béjar ${ }^{37}$. Doña Leonor tuvo que hacerse cargo en nombre de su hijo don Alonso, de solo nueve años, de la administración de dichas deudas. De hecho, a pesar de que en 1551 el VI duque había vinculado y agregado "el ornato de alhajas a su casa y mayorazgo", no tuvo lugar dicha vinculación, en virtud de una cláusula de la partición de los bienes que quedaron tras su muerte, que establecía cómo "en caso de no alcanzar el valor de todos los vienes libres al importe de sus deudas no se tengan por vinculados aquellos que dicho Señor ha agregado al Vinculo y Maiorazgo", adjudicándose "como vienes libres a dicho Señor Conde de Niebla pagador de deudas" 38 . Puede que en este momento y para pagar parte de estas deudas heredadas, se vendieran en pública almoneda los bustos de las dos vírgenes, junto con otras alhajas

\footnotetext{
${ }^{36}$ Ibidem, p. 344. Transcripción de Fernando Cruz Isidoro.

37 ADMS, leg. 942, op. cit.

38 Ibidem.
} 
y objetos que aparecen recogidos en el inventario post mortem, elaborado seguramente a tal efecto.

Otras posibilidades son que don Alonso Pérez de Guzmán el Bueno, VII duque de Medina Sidonia, entregara los bustos de las vírgenes a alguna de sus hijas, como parte de la dote, o bien que los depositara en alguna otra de las numerosas fundaciones religiosas de la Casa. También es posible que de alguna forma-compra o regalo- terminaran formando parte de la colección de otra rama secundaria de la familia. Cualquiera de estas opciones explicaría la pervivencia de los escudos, como un recuerdo del origen familiar de los relicarios.

\section{CONCLUSIONES}

Como consecuencia del presente estudio, realizado basándonos en una investigación combinada de los aspectos técnicos, históricos, documentales e iconográficos, se ha podido concluir que los cuatro bustos analizados forman parte de un conjunto de veintiséis piezas de gran interés y extraordinaria calidad artística, realizadas en Bruselas, sin duda por el taller de los Borman, estrechamente relacionadas entre sí y que, por ello, deben ser consideradas en cierto modo como una unidad.

Por otro lado, se ha probado que los bustos relicario de la basílica de la Caridad de Sanlúcar de Barrameda pertenecieron al VI duque de Medina Sidonia y que originalmente formaron parte de un grupo de cuatro relicarios del séquito de Santa Úrsula: los obispos San Eusebio y San Columbino, que se encuentran en dicha iglesia, y las vírgenes Santa Bonifacia y Santa Lucencia, hoy en el Hearst Castle de San Simeón. Lo que, a pesar de las transformaciones que han sufrido, permite establecer una hipótesis clara de cómo debieron ir decorados en origen los obispos de Sanlúcar.

Como consecuencia de todo ello, en este momento se puede afirmar que al menos dieciocho bustos del grupo pertenecieron a miembros de la corte y consejos de la Cesárea Majestad -los cuatro de Úbeda, los dos de Astorga, los cinco de Vitoria, los dos de Joarilla, los dos de Sanlúcar, los dos de San Simeón y el de Berlín-. En el caso de los otros ocho relicarios -los dos de Barcelona, los cuatro de Nueva York, el de Los Ángeles y el de la colección Spitzer-, por ahora carecemos de datos para asegurarlo. Pero dado que coindiden en el resto de aspectos estudiados, características técnicas, iconografía o estilo, no dudamos que compartan esa relación con los viajes del emperador y su corte por Europa, o sus visitas a la iglesia de Santa Úrsula, en Colonia ${ }^{39}$, como sostienen casi todos los especialistas que han tratado sobre el tema.

${ }^{39}$ FERREIRO, Joaquín: La leyenda ..., op. cit., pp. 114-120. 
Por último, teniendo en cuenta la calidad de los bustos de la iglesia de la $\mathrm{Ca}$ ridad, las transformaciones que han sufrido y el estado de conservación que presentan, sería deseable que estas piezas fueran convenientemente restauradas y sometidas a un riguroso estudio técnico que permitiera establecer el número de piezas originales y añadidas, si conservan reliquias en su interior, u obtener cualquier otra información relevante. No habría que descartar que la repolicromía, que cubre toda su superficie y empasta la finura de la talla que caracteriza la obra de este taller, oculte decoraciones o elementos que pudieran servir para relacionar estas piezas con la Casa de Medina Sidonia o con la coronación del emperador, como en el caso del obispo de Berlín.

También sería deseable profundizar en el estudio histórico de los bustos que se encuentran actualmente en San Simeón, para recabar datos relativos a su salida de Sanlúcar, su incorporación al mercado artístico o su exportación, así como completar el análisis de los aspectos técnicos, para determinar el número de piezas, la presencia de reliquias en su interior o cuándo se añadieron los escudos de armas. Estudio exhaustivo que sería conveniente extender y combinar con el del resto de los bustos del grupo.

Fecha de recepción: 30 de septiembre de 2017

Fecha de aceptación: 12 de abril de 2018 


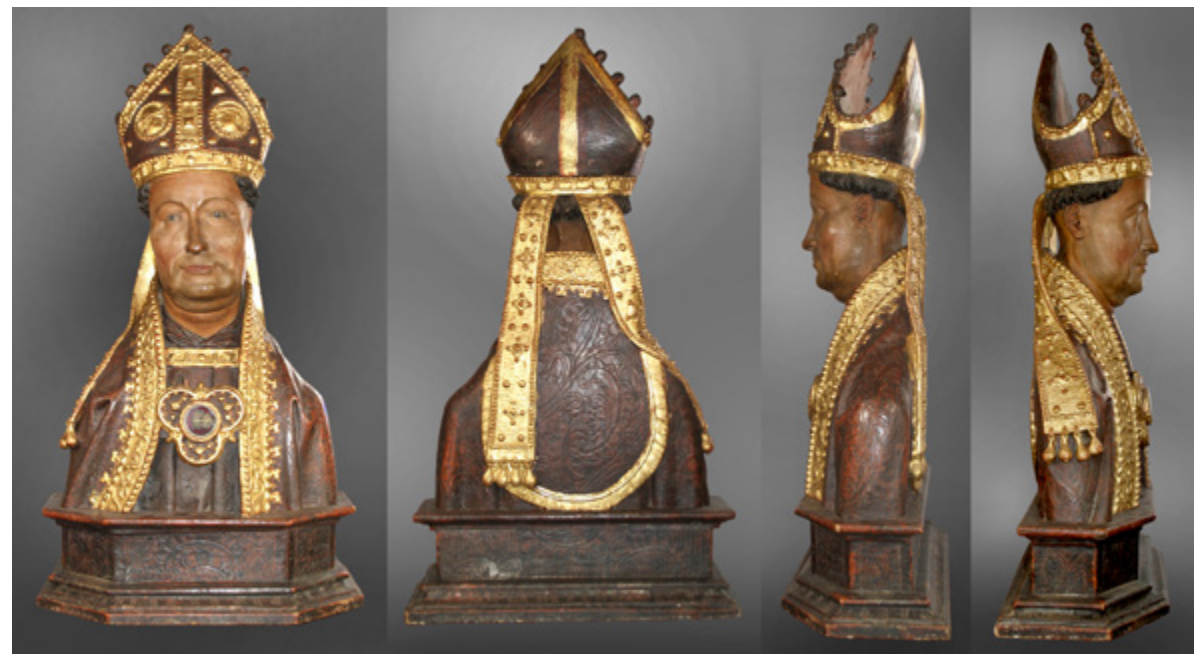

Figura 1. Busto relicario de San Eusebio, basílica de Nuestra Señora la Caridad, Sanlúcar de Barrameda.

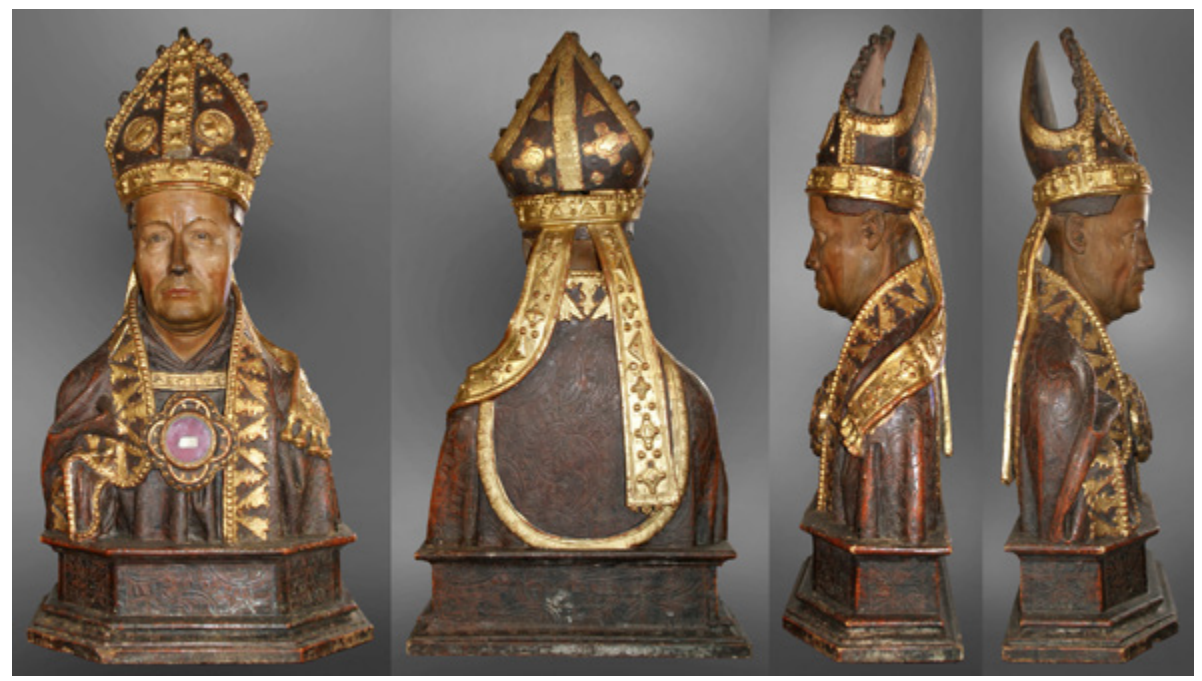

Figura 2. Busto relicario de San Columbano, basílica de Nuestra Señora la Caridad, Sanlúcar de Barrameda. 


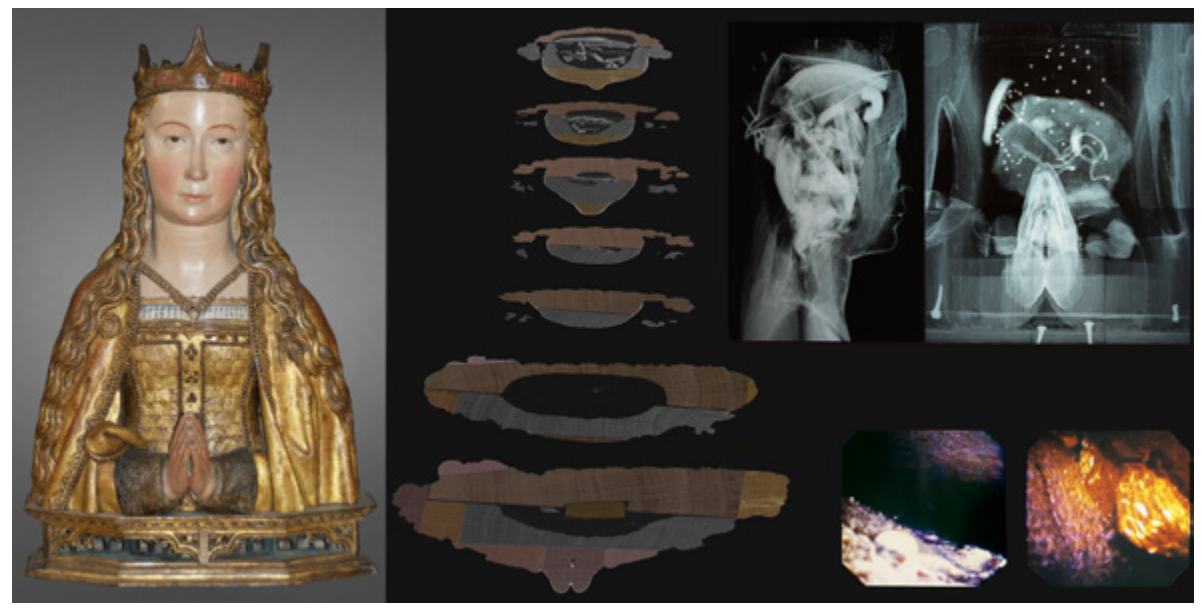

Figura 3. Imágenes del estudio tomográfico, radiográfico y endoscopia del busto relicario de Santa Balbina, Museo Diocesano de Arte Sacro de Vitoria.

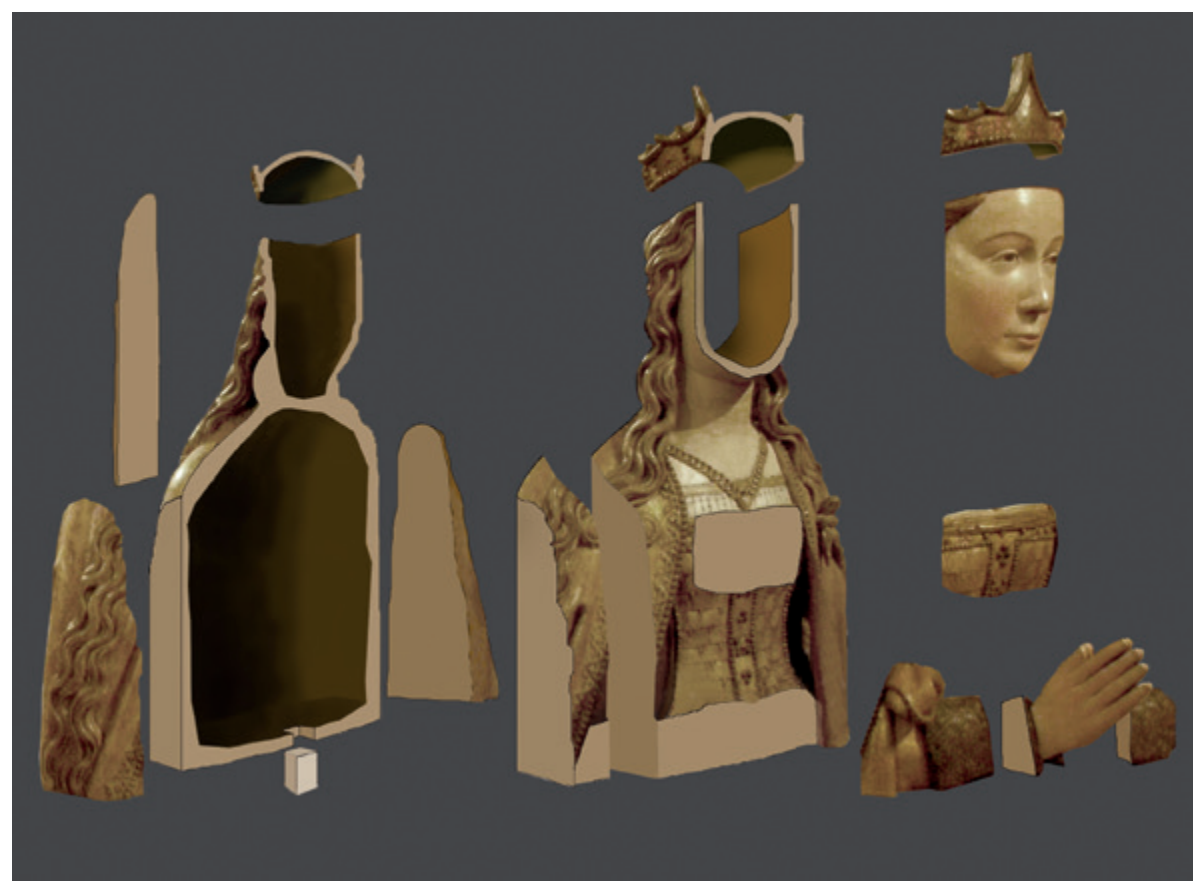

Figura 4. Reconstrucción digital de la distribución de las piezas del busto relicario de Santa Balbina, Museo Diocesano de Arte Sacro de Vitoria. 


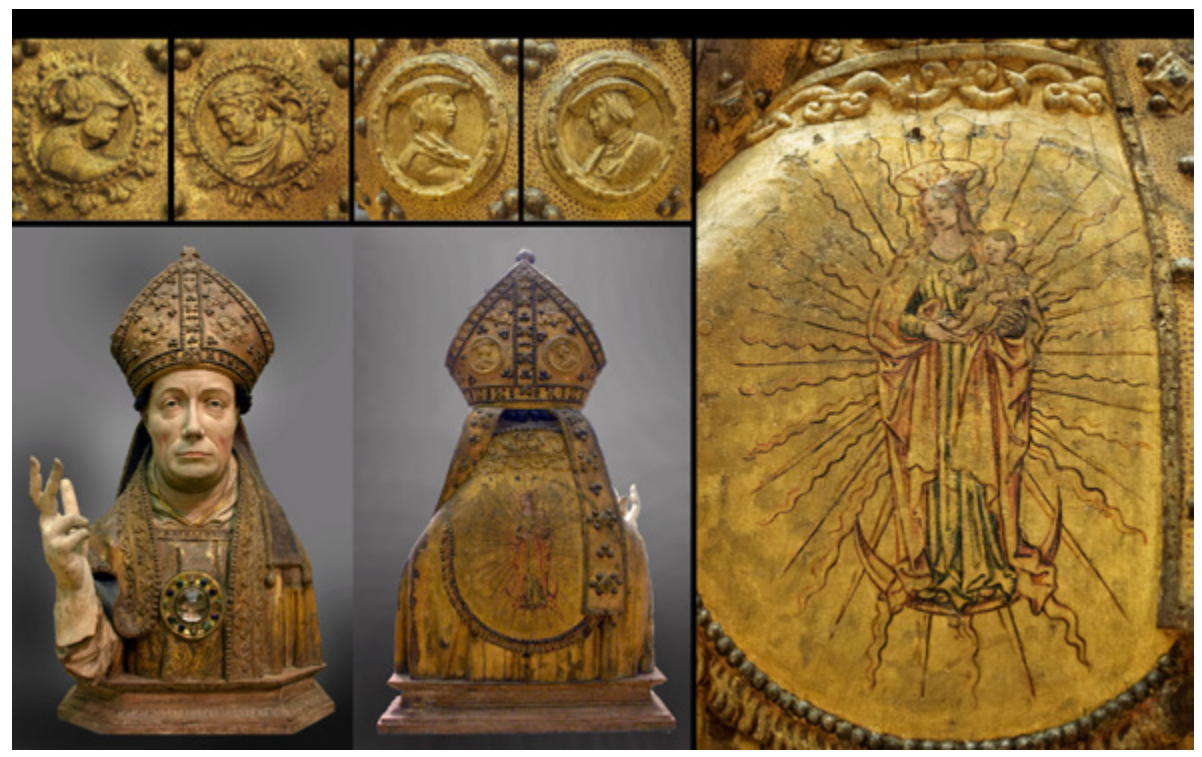

Figura 5. Detalles de los medallones de la mitra y del capillo del busto relicario de obispo, Bode Museum, Berlín.

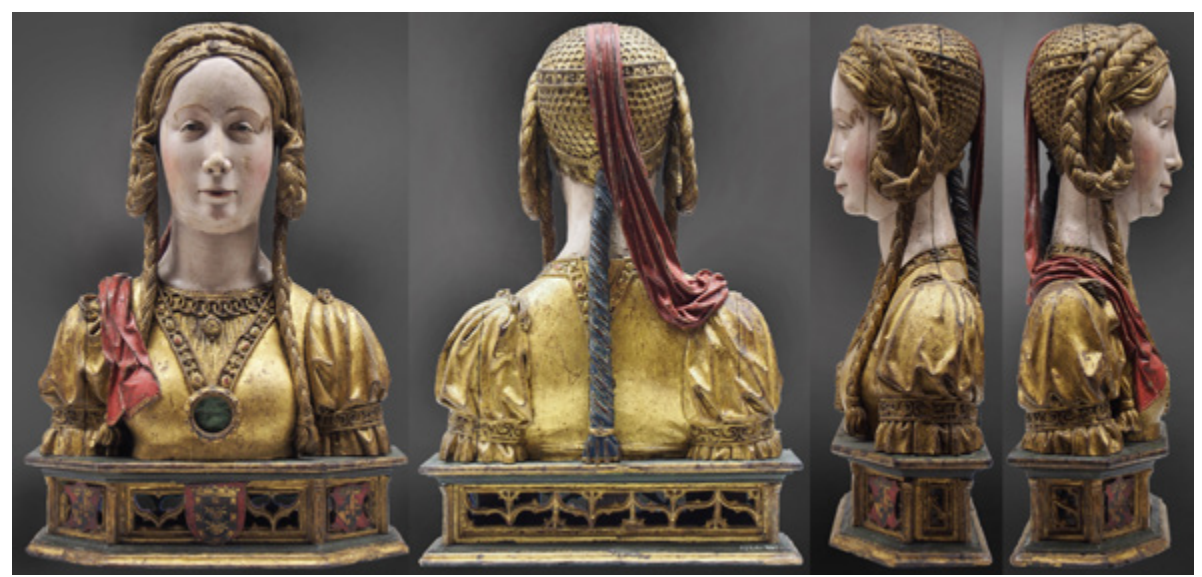

Figura 6. Busto relicario de santa, $\mathrm{n}^{\circ}$ 529-9-931, Hearst Castle-California State Parks, San Simeón. 


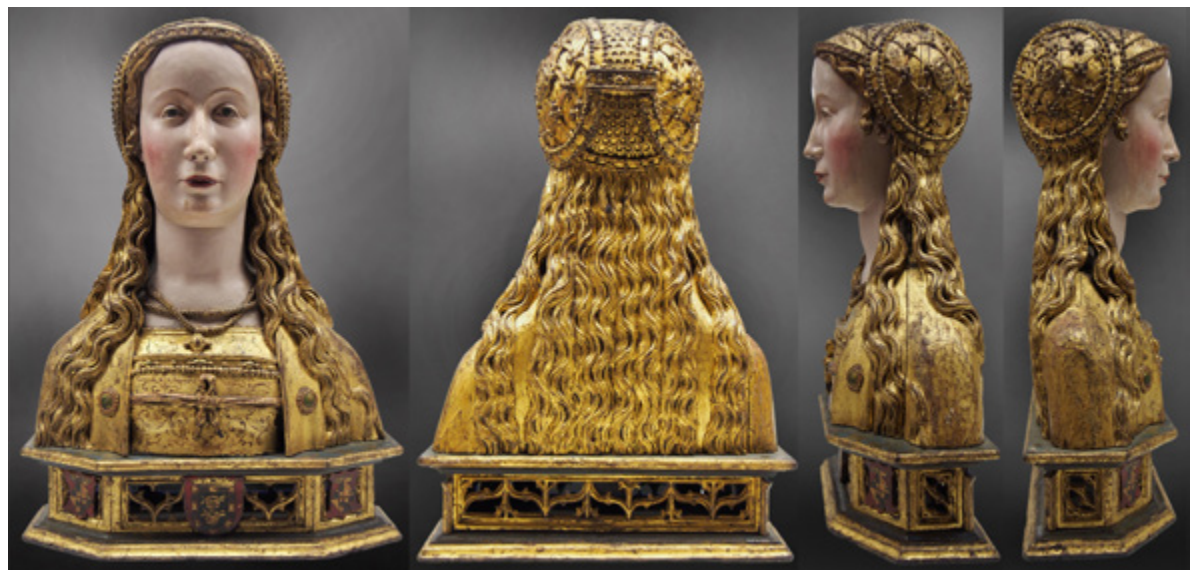

Figura 7. Busto relicario de santa, $\mathrm{n}^{\circ}$ 529-9-932, Hearst Castle-California State Parks, San Simeón. 


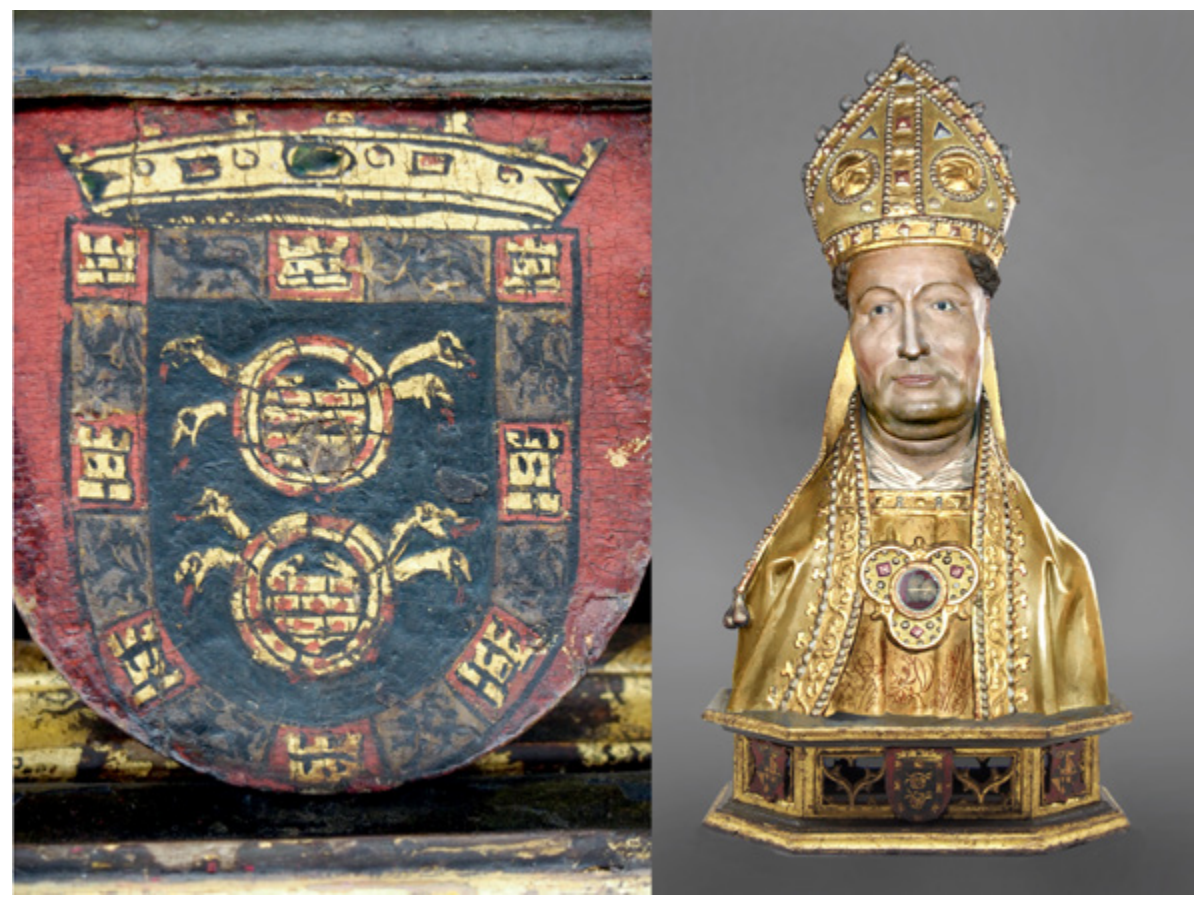

Figura 8. Detalle de uno de los escudos de Medina Sidonia en una de las peanas de San Simeón y reconstrucción digital de la hipótesis del aspecto original del busto de San Eusebio. 